\title{
Total Intravenous Anaesthesia
}

\author{
N. L. Padfield (ed) \\ Butterworth Heinemann: Oxford, UK, 2000, 306 pp; indexed, illustrated \\ ISBN: 0-7506-4171-1; Price £35.00
}

The book provides an excellent introduction to total intravenous anaesthesia (TIVA). The editor has used a total of 15 contributors, including several leading authorities on the subject, and the text is fully referenced. As the foreword points out, the introduction of propofol has revolutionized the practice of TIVA and this is reflected in the book. Although other agents are considered, the emphasis is on the use of propofol, short-acting opioids and target-controlled infusions.

The book is split into three parts, the first of which provides a general overview of TIVA, including chapters on its history, pharmacology and basic clinical application. The chapter on pharmacokinetics manages to deal with a complex subject, reasonably, succinctly and the use of diagrams in this chapter helps considerably. The last chapter in this section, on administration of TIVA, has some particularly helpful clinical scenarios. The second part of the book deals with related issues, specifically postoperative nausea and vomiting and awareness. The bulk of the book, however, is contained in the third part and this deals with the application of TIVA to a variety of subspecialties. There are chapters devoted to its use not only in day case surgery, but also to cardiothoracic, neurosurgical, plastic/ear, nose and throat and endocrine surgery. These chapters highlight areas where the use of TIVA is becoming the technique of choice rather than a useful alternative.

In all, the editor has managed to produce a fully comprehensive but accessible text with a 'hands on' feel to it. I have few criticisms as I think this book achieves exactly what it sets out to do, i.e. to provide an excellent starting point for those wishing to familiarize themselves with the technique of TIVA. It would also serve as a useful reference book for those preparing for examinations and it certainly deserves a place in every departmental library.

M. A. M. Gillies London, UK

\section{Atlas of Pain Injection Techniques}

\author{
T. O'Connor, S. Abram \\ Churchill Livingstone: Edinburgh, UK, 2003, 141 pp; indexed, illustrated \\ ISBN: 0-443-06380-X; Price £49.99
}

Being the author of a technical manual carries with it a great responsibility. The text must be easy to understand with no ambiguity. Similarly, diagrams and photographs must be of a high standard with clear labelling. Unfortunately, relatively few manuals of technique reach this high standard.

Therese O'Connor and Stephen Abram appear to have tried to achieve a text of excellence by focusing on a relatively small number of basic techniques. Their approach has been to cover the methodology in a systematic manner. Unfortunately, this gamble does not appear to have paid off. This has resulted in introductions that are too brief and descriptions of technique that are repetitive. Important variations in technique are lost in the text because of the presentation and, as a result, there is a risk of making a 
mistake. When I compared their description of some techniques to other texts that are available, I usually found the other books easier to follow! There was no justification of the approach used in their book over any other and the text is not supported by references.

O'Connor and Abram certainly have some very nice line diagrams, but labelling was poor and Figure legends hidden in the text. It is much easier to read the legend close to the diagram and not as a part of the text! Many of the diagrams appeared to be an over simplification and some simple line diagrams were repeated on numerous occasions. The quality of the radiograph and computerized tomography reprints was low by today's standard.

Whereas I accept that there will always be a personal touch to procedures, I was disappointed by the approach that they used for certain techniques. For instance, I was surprised to see radiographs being used, as opposed to continuous imaging, to confirm needle placement for facet joint injections. Also, I wonder about the use of Esmarch bandages, presumably for patients with complex regional pain syndrome, in their description of intravenous regional sympathetic blocks. I doubt that my patients would tolerate this.

This book needs a better introduction on general principles and the chapters on drugs used need to be expanded. In addition, a chapter on block needles and nerve stimulators needs to be considered. Unfortunately, this book will sit on my shelf and be rarely used by trainees or myself.

\section{A. Baranowski London, $U K$}

\title{
Medicine and Art
}

\author{
Alan Emery, Marcia Emery \\ Royal Society of Medicine Press: London, UK, 2003, 111pp; illustrated \\ ISBN: 1-85315-501-2; Price £40.00 (bbk)
}

The fascination of medical topics and illness for artists through the ages mirrors the fascination of the general population. In Medicine and Art, Professor Emery and his wife have collected a series of illustrations portraying medicine and medical practice from antiquity; from an Egyptian statue and a Greek amphora to a collage of the twenty-first century. Each painting or drawing is accompanied by a brief but comprehensive description of medicine and medical practice during the period at the time of the creation of the artwork and a brief outline of the artist and his career. In many instances, the artists are either accredited masters themselves or pupils of artists who had a significant influence on the development of art through the ages.

For instance, Pietro Lorenzetti (active 1320-1348 St Humility Healing a Sick Nun (circa. 1341)) was a Sienese painter who was directly influenced by Giotto (1266-1337). The Dutch genre painter Gerrit Dou (1613-1764 - The Quack Doctor (1650) and The Physician (1653)) had a linear style that contrasts with the painterly style of his teacher Rembrandt. The subtle humour of both William Hogarth
(1697-1764 - Marriage a la mode: the Inspection (1743)) and Thomas Rowlandson (1756-1827 - The Consultation or Last Hope (1808)) is well demonstrated in the chosen pictures. In the latter, the problems of gross obesity are graphically illustrated! The paintings of Vincent van Gogh (1853-1890 - The Hospital at Aries (1890)), Edvard Munch (1863-1944 - Death in the Sick Room (1893)), Stephen Conroy (1964 Healing of a Lunatic Boy (1986)) and Sergi Chepik (1953 - The Madhouse (1987)) portray an aspect of psychiatry, both personal and environmental. The painting by Pablo Picasso (1881-1973 - Science and Charity (1897)) is from a period of his career with which many of us are unfamiliar and demonstrates his immense early talent. Other paintings by Henry Tonks, Stanley Spencer, Andrew Wyeth and L. S. Lowry all contribute to a fascinating collection of art related to the medical world, which provide a source of stimulus to the enquiring reader. 


\section{ERRATUM:}

Rowbotham DJ. COX-2-selective inhibitors: clinical relevance in surgical and acute pain. Eur J Anaesthesiol 2002; 19 (Suppl. 25): 11-20.

The chemical structure for rofecoxib is incorrectly shown as a sulphonamide when it should be a methyl sulphone. Thus $-\mathrm{NH}_{2}$ should be replaced by $-\mathrm{CH}_{3}$. 